\title{
Single-walled Carbon Nanotube-triethylammonium Ionic Liquid as a New Catalytic System for Michael Reaction
}

\author{
Pankaj Attri, ${ }^{*}$ Eun Ha Choi, Gi-Chung Kwon, ${ }^{*}$ Rohit Bhatia, ${ }^{\dagger}$ Jitender Gaur, ${ }^{\ddagger}$ Bharti Arora, ${ }^{\S}$ and In Tae Kim ${ }^{\sharp, *}$ \\ Plasma Bioscience Research Center/Department of Electrical and Biological Physics, Kwangwoon University, \\ Seoul 139-701, Korea. E-mail: chem.pankaj@gmail.com (P.Attri); gckwon@kw.ac.kr (G.-C.Kwon) \\ †Department of Chemistry, University of Delhi, Delhi 110007, India \\ ¿CSIR-National Physical Laboratory, Dr. K. S. Krishnan Marg, New Delhi 110012, India \\ ${ }^{\S}$ Department of Applied Sciences and Humanities, ITM University, Sector-23(A) Gurgaon 122017, Haryana, India \\ "Department of Chemistry, Kwangwoon University, Seoul 139-701, Korea. "E-mail: itkim@kw.ac.kr \\ Received May 22, 2014, Accepted June 30, 2014
}

\begin{abstract}
A new efficient catalytic method for aza/thia-Michael addition reactions of amines/thiols with higher product yields has been developed. Combining single-walled carbon nanotubes (SWCNT) with triethylammonium hydrogen phosphate (TEAP) ionic liquid (IL) can work as a catalyst. We utilized Raman spectroscopy to gain insight into the interactions between IL and SWCNT. The interactions between SWCNT with TEAP were confirmed by the increasing intensity ratios and spectral shift in wavelength of the Raman D and G bands of SWCNT. Further, the morphology of the resulting composite materials of TEAP and SWCNT was determined by using scanning electron microscopy (SEM). Higher product yield in reduced reaction time is the key advantage of using bucky gel as a catalyst for Michael reaction.
\end{abstract}

Key Words : Michael reaction, Single-walled carbon nanotubes, Triethylammonium hydrogen phosphate, Scanning electron microscopy, Confocal Raman spectroscopy

\section{Introduction}

Carbon nanotubes (CNTs) and ionic liquids (ILs) are one such interesting class of materials having unique properties and a wide range of applications. ${ }^{1-8}$ Organic cations weakly coordinated with inorganic/organic anion possessing desirable properties, and existing as liquids at or close to room temperature are commonly known as ionic liquids. ${ }^{5,6}$ ILs have proven to be promising solvents for various applications such as organic synthesis, protein folding, materials science, electrochemistry and separation technology. ${ }^{9-15}$ On the other hand, the carbon nanotube (CNTs) due to their large surface area and exceptional electric properties are being exploited for the development of nanostructured materials with various applications. ${ }^{1,2}$ But the presence of strong van der Waals attraction among CNTs makes it difficult to disperse CNTs homogeneously in both organic and aqueous solvents, which limits their application in many fields. In order to provide a solution to this problem, ILs were used to disperse CNTs. ${ }^{16,17}$ Nowadays, scientist are keen interested in exploring the properties and interactions of ILs and CNTs. ${ }^{16-24}$ Dispersing CNTs with ILs results in soft materials, commonly known as bucky gels are in high demand and are found to have wide variety of usage in chemical, physical and biological applications. ${ }^{2}$

It was first reported by Fukushima et al., ${ }^{16}$ that imidazolium based ILs, such as 1-butyl-3-methylimidazolium tetrafluoroborate by grinding with single walled carbon nanotubes (SWCNTs) can form gel called "bucky gels". Later, Wang et al., ${ }^{25}$ indicated the possibility of weak van der
Waals interaction between imidazolium-based ILs and SWCNTs. Kocharova et al., ${ }^{26}$ further reported that carbon nanotubes can be effectively dispersed in aqueous solutions by 1-dodecyl-3-methylimidazolium bromide and 1-(12-mercaptododecyl)-3-methylimidazolium bromide. Further, Aida and Lee confirmed the formation of bucky gels when imidazolium ion-based ILs were grounded with SWCNTs. ${ }^{27}$ Although Zhou et al., ${ }^{28}$ investigated that CNTs could be dispersed stably in water with the aid of very small amounts of the 1-aminoethyl-3-methylimidazolium bromide and 1(2-aminoethyl)-pyridinium bromide. The stability of 1-hexadecyl-3-vinyl-imidazolium, a water-soluble long-chain IL possessing properties of surfactants so as to disperse SWCNTs was interpreted by Crescenzo et al. ${ }^{29}$ Additional, Fukuda et al., ${ }^{30}$ fabricated a Braille sheet with a CNT-based actuator composed of SWCNT and ILs. Recently, Moham-madi and Foroutan explored the structural characteristics along with the dispersion of the aggregated non-bundled and bundled CNTs in an IL (1- $n$-propyl-4-amino-1,2,4-tri-azolium bromide).$^{18}$ These results revealed that, ILs due to their unique properties (e.g., low flammability, low or zero volatility, high thermal stability and ionic conductivity) are a better CNT dispersant than the conventional organic solvents. And, the bucky gel so formed founds usage in variety of electrochemical applications such as biosensors, capacitors and actuators. ${ }^{18,24}$ These composite materials can also be used as immobilizing matrices electrochemical biosensors to entrap proteins and enzymes that provide a favorable microenvironment for redox proteins and enzymes. This retains their bioactivity, and is also helpful in performing direct 
electrochemistry and electrocatalysis. ${ }^{24}$ Since, the use of CNT-IL in organic synthesis is very limited so, to exploit the bucky gel for organic reactions, we examined the Michael reactions under the influence of CNT-IL.

Michael reaction has been studied for more than one century. ${ }^{31-43}$ It has been extensively used for the synthesis of $\beta$-amino carbonyl structural motifs which are embedded in a wide range of pharmaceutical intermediates, peptide analogues, antibiotics, and other biologically active molecules and drugs. ${ }^{31-35} \beta$-Amino carbonyl compounds represent versatile building blocks for the synthesis of $\beta$-amino acid derivatives, amino alcohols, diamines and many of which serve as important antibiotics or other drugs. ${ }^{31}$ Michael reaction provides a promising method due to its simplicity and atom economy. The aza-Michael reaction involves the reaction of activated alkenes and amines. While, the thia-Michael addition to $\alpha, \beta$-unsaturated carbonyl compounds provide a practical strategy for the selective protection of $\mathrm{C}=\mathrm{C}$ bonds of conjugated enones.

Unfortunately, the reaction suffers from many limitations, such as the use of expensive reagents, harsh conditions, relatively long reaction times, high catalyst loading, low selectivity, presence of side reactions, and tedious work-up procedures for their separation, recycling, or disposal problems and effluent pollution. All these limitations forced us to explore a new, more efficient catalyst with limited drawbacks. ${ }^{36-43}$ So, we have tried to develop a new catalytic system that has characteristic properties such as good thermal and mechanical stabilities of supported reagents, and is easy treatable, low toxic, non-corrosive, easy separable from reaction mixture through filtration, and also feasible for reuse. Recently, we have developed a catalytic system using triethylammonium dihydrogen phosphate (TEAP) and MWCNT and successfully used this to synthesis Michael reaction. ${ }^{44}$ In this work, we have reported the SWCNT-TEAP bucky gel characterization and its application as catalyst for Michael reaction.

\section{Experimental Details}

CNTs (single-walled carbon nanotube and multiwalled carbon nanotube) were obtained from Sigma-Aldrich (USA). All the reagents used were of AR grade. Melting points were determined using a Thomas Hoover melting point apparatus and are uncorrected. ${ }^{1} \mathrm{H}(400 \mathrm{MHz})$ and ${ }^{13} \mathrm{C}$ NMR (100 $\mathrm{MHz}$ ) spectra were recorded on a Jeol 400 NMR spectrometer in $\mathrm{CDCl}_{3}$ (with TMS for ${ }^{1} \mathrm{H}$ and chloroform- $d$ for ${ }^{13} \mathrm{C}$ as internal references) unless otherwise stated. The Raman spectra were measured at room temperature using a confocal Raman microscope (WITec, Alpha $300 \mathrm{R}$ ) with a $514 \mathrm{~nm}$ He-Ne laser. The reactions were monitored by Thin Layer chromatography (TLC) using aluminum sheets with silica gel $60 \mathrm{~F}_{254}$ (Merck). Gas chromatography-mass spectrometry from Agilent Technologies 7890 GC. CNTs can be easily dispersed in the TEAP based room temperature IL by mechanically milling, forming a thermally stable bucky gel as follows. ${ }^{16,25,44}$
General Procedure for the Preparation of Entry 1-5 by aza-Michael Reaction. A solution of amine $(1 \mathrm{mmol})$ and $\alpha, \beta$-unsaturated nitriles or carbonyl compounds $(1.2 \mathrm{mmol})$ was added to SWCNT-TEAP (1 mg) and the mixture was stirred at $25^{\circ} \mathrm{C}$ for $1 \mathrm{~min}$. The completion of the reactions was monitored using TLC. The product formed in the onephase system, was extracted with diethyl ether. The resulting organic phase extract was washed with a saturated aqueous $\mathrm{NaHCO}_{3}$ solution, and then dried over anhydrous $\mathrm{Na}_{2} \mathrm{SO}_{4}$. The solvent was removed and the residue was further purified by recrystallization or silica gel chromatography. The reaction products were analyzed with ${ }^{1} \mathrm{H}$ and ${ }^{13} \mathrm{C}$ NMR spectroscopy. ${ }^{1} \mathrm{H}$ and ${ }^{13} \mathrm{C}$ NMR of entry $1-5$ are given below:

3-[4-(4-Nitrophenyl)piperazin-1-yl]propionitrile (entry 1): Yellow solid, mp $92-94{ }^{\circ} \mathrm{C} ;{ }^{1} \mathrm{H}$ NMR $\left(\mathrm{CDCl}_{3}\right) \delta 2.68(\mathrm{~m}$, $8 \mathrm{H}), 3.44$ (d, $J=4.5 \mathrm{~Hz}, 4 \mathrm{H}), 6.81$ (d, $J=9.12 \mathrm{~Hz}, 2 \mathrm{H}), 8.10$ $(\mathrm{d}, J=9.06 \mathrm{~Hz}, 2 \mathrm{H}) .{ }^{13} \mathrm{C} \mathrm{NMR}\left(75 \mathrm{MHz}, \mathrm{CDCl}_{3}\right) \delta 16.0$, 46.8, 52.0, 53.0, 112.7, 118.4, 125.8, 138.5, 154.6.

3-[4-(4-Aminophenyl)piperazin-1-yl]propionitrile (entry 2): Brown solid, mp $92-94{ }^{\circ} \mathrm{C} ;{ }^{1} \mathrm{H}$ NMR $\left(\mathrm{CDCl}_{3}\right) \delta 2.56(\mathrm{t}, J$ $=6.7 \mathrm{~Hz}, 2 \mathrm{H}), 2.65(\mathrm{t}, J=4.5 \mathrm{~Hz}, 4 \mathrm{H}), 2.76(\mathrm{t}, J=6.7 \mathrm{~Hz}$, $2 \mathrm{H}), 3.05(\mathrm{t}, J=4.6 \mathrm{~Hz}, 4 \mathrm{H}), 3.29(\mathrm{~s}, 2 \mathrm{H}), 6.64(\mathrm{~s}, 2 \mathrm{H}), 6.80$ $(\mathrm{d}, J=8.2 \mathrm{~Hz}, 2 \mathrm{H}) .{ }^{13} \mathrm{C} \mathrm{NMR}\left(\mathrm{CDCl}_{3}\right) \delta 15.7,30.6,50.7$, 52.7, 53.2, 116.0, 118.6, 140.2, 144.1.

3-[4-[(Benzo[1,3]dioxol-5-yl)methyl]piperazin-1-yl]propionitrile (entry 3): Mustard colour oil; ${ }^{1} \mathrm{H} \mathrm{NMR}\left(\mathrm{CDCl}_{3}\right) \delta$ 2.49 (m, 10H), 2.68 (t, $J=6.98 \mathrm{~Hz}, 2 \mathrm{H}), 3.40$ (s, 2H), 5.93 $(\mathrm{s}, 2 \mathrm{H}), 6.73(\mathrm{~s}, 2 \mathrm{H}), 6.83(\mathrm{~s}, 1 \mathrm{H}) .{ }^{13} \mathrm{C} \mathrm{NMR}\left(\mathrm{CDCl}_{3}\right) \delta 15.6$, 31.7, 52.5, 53.1, 62.4, 100.7, 107.7, 109.3, 122.0, 138.0, $148.5,151.2$.

3-[4-(4-Chlorophenyl)piperazin-1-yl]propionitrile (entry 4): Light yellow solid, mp $98-100{ }^{\circ} \mathrm{C} ;{ }^{1} \mathrm{H} \mathrm{NMR}\left(\mathrm{CDCl}_{3}\right) \delta$ $2.55(\mathrm{t}, J=6.8 \mathrm{~Hz}, 2 \mathrm{H}), 2.66(\mathrm{t}, J=4.6 \mathrm{~Hz}, 4 \mathrm{H}), 2.74(\mathrm{t}, J=$ $6.9 \mathrm{~Hz}, 2 \mathrm{H}), 3.17(\mathrm{t}, J=4.6 \mathrm{~Hz}, 4 \mathrm{H}), 6.83(\mathrm{~d}, J=6.9 \mathrm{~Hz}$, 2H), $7.20(\mathrm{~d}, J=6.9 \mathrm{~Hz}, 2 \mathrm{H}) .{ }^{13} \mathrm{C} \mathrm{NMR}\left(75 \mathrm{MHz}, \mathrm{CDCl}_{3}\right) \delta$ 15.9, 49.0, 52.5, 117.3, 118.5, 124.7, 128.9, 149.6.

3-(4-Phenylpiperazin-1-yl) cyclohexanone (entry 5): Colorless oil: ${ }^{1} \mathrm{H}$ NMR $\left(\mathrm{CDCl}_{3}\right) \delta 1.71(\mathrm{~m}, 2 \mathrm{H}), 2.1(\mathrm{~m}, 2 \mathrm{H})$, $2.4(\mathrm{~m}, 3 \mathrm{H}), 2.8(\mathrm{~m}, 6 \mathrm{H}), 3.20(\mathrm{t}, J=4.95 \mathrm{~Hz}, 4 \mathrm{H}), 7.92(\mathrm{~m}$, $3 \mathrm{H}), 7.29(\mathrm{~m}, 2 \mathrm{H}) .{ }^{13} \mathrm{C} \mathrm{NMR}\left(\mathrm{CDCl}_{3}\right) \delta 22.4,28.1,41.2$, 44.4, 48.9, 49.5, 63.2, 116.1, 119.8, 129.1, 151.2, 210.5 .

General Procedure for the Preparation of Entry 6-8 by thia-Michael Reaction. A solution of thiol $(1 \mathrm{mmol})$ and $\alpha, \beta$-unsaturated nitriles or carbonyl compounds $(1.2 \mathrm{mmol})$ was added to SWCNT-TEAP (1 mg) and the mixture was stirred at $25{ }^{\circ} \mathrm{C}$ for $1 \mathrm{~min}$. The completion of the reactions was again monitored using TLC. The product formed in the one-phase system, was further extracted with diethyl ether. The resulting organic phase extract was washed with a saturated aqueous $\mathrm{NaHCO}_{3}$ solution, and then dried over anhydrous $\mathrm{Na}_{2} \mathrm{SO}_{4}$. The solvent was removed and the residue was purified by recrystallization or silica gel chromatography. The reaction products were then analyzed with ${ }^{1} \mathrm{H}$ and ${ }^{13} \mathrm{C}$ NMR spectroscopy. ${ }^{1} \mathrm{H}$ and ${ }^{13} \mathrm{C}$ NMR of entry 6,7 are given below:

3-(2-Methoxyphenylsulfanyl)butyraldehyde (entry 6): Colorless oil; ${ }^{1} \mathrm{H} \mathrm{NMR}\left(\mathrm{CDCl}_{3}\right) \delta 2.68(\mathrm{~m}, 3 \mathrm{H}), 3.89(\mathrm{~s}, 3 \mathrm{H})$, 
$6.89(\mathrm{~m}, 3 \mathrm{H}), 7.32(\mathrm{~m}, 1 \mathrm{H}) \cdot{ }^{13} \mathrm{C} \mathrm{NMR}\left(\mathrm{CDCl}_{3}\right) \delta 21.0,35.8$, 50.2, 55.7, 110.9, 121.0, 121.3, 127.6, 129.4, 159.1, 200.9.

3-p-Tolylsulfanyl-butyraldehyde (entry 7): Colorless oil; ${ }^{1} \mathrm{H}$ NMR $\left(\mathrm{CDCl}_{3}\right) \delta 1.36(\mathrm{~d}, J=6.90 \mathrm{~Hz}, 3 \mathrm{H}), 2.42$ (s, $3 \mathrm{H}), 2.62(\mathrm{~m}, 2 \mathrm{H}), 3.69(\mathrm{~m}, 1 \mathrm{H}), 7.36(\mathrm{~m}, 4 \mathrm{H}), 9.75(\mathrm{~s}, 1 \mathrm{H})$. ${ }^{13} \mathrm{C}$ NMR $\left(\mathrm{CDCl}_{3}\right) \delta 20.8,21.0,36.9,50.2,126.5,126.7$, 127.5, 130.5, 132.6, 133.3, 140.2, 200.4 .

Synthesis of Triethylammonium Dihydrogen Phosphate (TEAP). The synthesis of ionic liquids was carried out in a $250 \mathrm{~mL}$ round-bottomed flask, which was immersed in a water-bath and fitted with a reflux condenser. Phosphoric acid $(1 \mathrm{~mol})$ was dropped into the triethyl amine $(1 \mathrm{~mol})$ at $70{ }^{\circ} \mathrm{C}$ for $1 \mathrm{~h}$. The reaction mixture was heated at $80{ }^{\circ} \mathrm{C}$ with stirring for $2 \mathrm{~h}$ to ensure that the reaction had proceeded to completion. The reaction mixture was then dried at $80{ }^{\circ} \mathrm{C}$ until the weight of the residue remained constant. The sample was analysed by Karl Fisher titration which revealed very low levels of water (below $70 \mathrm{ppm}$ ). The yield of TEAP was $198 \mathrm{gm}, \mathrm{mp} 92{ }^{\circ} \mathrm{C} ;{ }^{1} \mathrm{H}$ NMR (DMSO- $\left.d_{6}\right) \delta 1.18(\mathrm{t}, 9 \mathrm{H})$, $3.06(\mathrm{~m}, 6 \mathrm{H}), 6.37(\mathrm{~s}, 1 \mathrm{H})$.

\section{Result and Discussion}

In above mentioned approach, we have used a combination of IL (triethylammonium dihydrogen phosphate (TEAP)) and CNT (SWCNT) commonly known as bucky gel, for a catalyst of Michael reaction products. In this work, we further studied the interactions between SWCNT and TEAP using confocal Raman spectroscopy and the morphology of the resulting composite materials of TEAP and SWCNT using scanning electron microscope (SEM). Further, we used this bucky gel as a catalyst for aza/thia-Michael reaction. SWCNT can be easily dispersed in the TEAP IL by mechanically milling, forming a thermally stable gel. ${ }^{16,24,27}$ There are many reports about the different kinds of bucky gel or soft materials, with variation in ILs or CNTs having various useful applications. ${ }^{18-27}$ But, the utility of bucky gel as a catalyst for organic reactions is still not documented well. In order to interpret the interactions between TEAP and SWCNT, confocal Raman spectroscopy proves to be advantageous in serving the vibrational energy of the target solutes as a reporter, which further eliminates the need for invasive monitoring aids such as molecular probes as is the case of confocal scanning laser microscopy. ${ }^{45}$ However, with the increasing penetration of the bucky gel, the Raman signal diminishes strongly owing to the Raman scattering as well as attenuation of the excitation laser power. Thus, the laser can be directed inside the bucky gel without damaging it, maintaining a high selectivity and sensitivity. Hence, Raman spectroscopy is a convincing tool for the structural characterization of CNTs.

As was reported in Du et al. ${ }^{46}$ upshift of $22 \mathrm{~cm}^{-1}$ is noticed as the tangential G-band in Raman spectra in case of SWCNTs. These shifts pointed on the confirmation of the charge transfer from IL to SWCNT due to the cation- $\pi$ or $\pi-\pi$ interactions. Our experimental results are depicted as in the Raman spectra of SWCNT (magenta) and SWCNT-
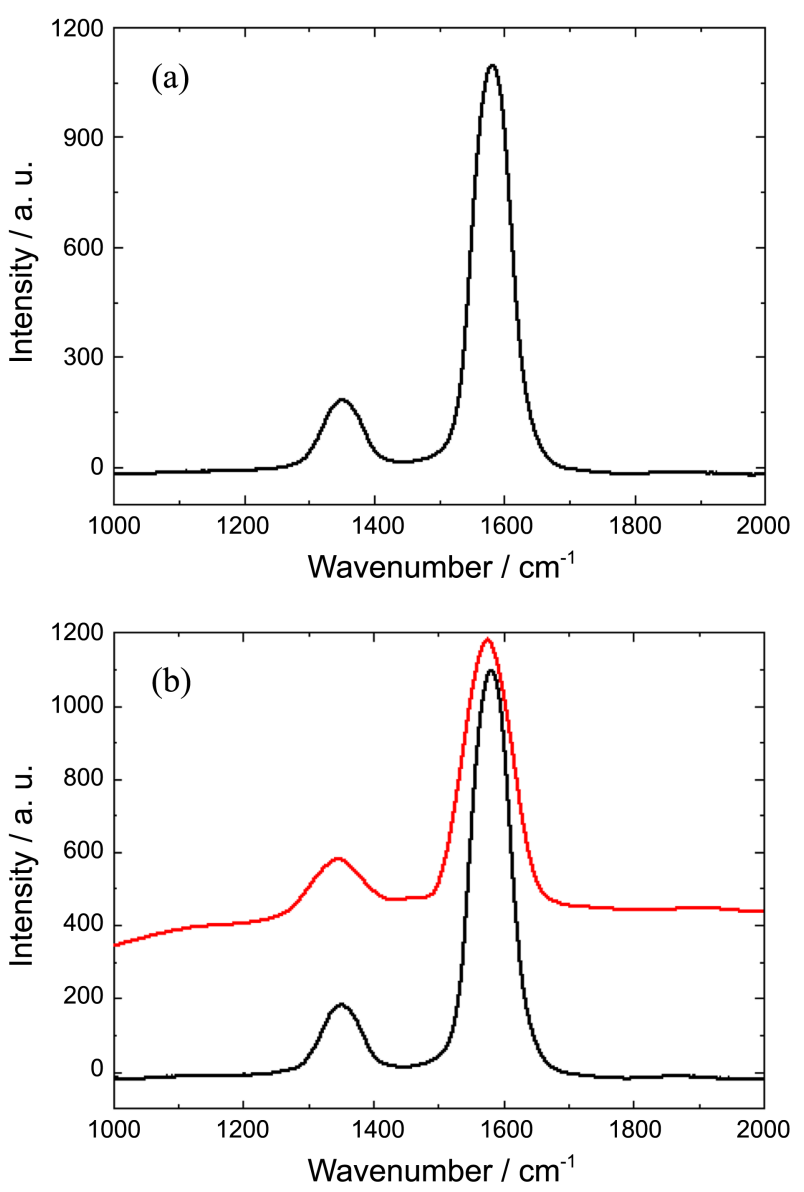

Figure 1. Raman spectra of (a) SWCNT (b) SWCNT (black) and SWCNT-TEAP (red).

TEAP (cyan) (Fig. 1(c)) where the D band shifts from 1349 to $1343 \mathrm{~cm}^{-1}$ and the $\mathrm{G}$ band shifts from 1583 to $1575 \mathrm{~cm}^{-1}$.

The Raman spectrum shows a typical D and G-peaks for SWCNT-TEAP which correspond to the presence of $\mathrm{sp}^{3}$ defects and vibration of $\mathrm{sp}^{2}$ carbon atoms in SWCNT sidewall, respectively. In addition, a G-peak position of SWCNTTEAP gels gets down shifted by $8 \mathrm{~cm}^{-1}$ compared to that of SWCNT, suggesting a noncovalent functionali-zation of TEAP on the graphitic structure of SWCNTs. Meanwhile, the driving force may come from the electro-static attraction between the SWCNT and TEAP. The possi-ble interactions between CNTs and TEAP may include the cation- $\pi$ and/or $\pi-\pi$ interactions that are evidenced by shift in wavelength of Raman spectrum, which has also been supported by the work of other research groups.

The morphology of the resulting SWCNT-TEAP was characterized by scanning electron microscopy (SEM). The pure SWCNT, pure MWCNT, TEAP, SWCNT-TEAP and and MWCNT-TEAP composites have different morphologies as was evidenced by their SEM images (Fig. 3). SEM images further suggest that SWCNT-TEAP gel composite produces more flat film morphology with a smoother surface. If we compared the SEM image of MWCNT-TEAP and SWCNTTEAP, we observed that in both the cases the TEAP has uniformally cover the CNTs. 

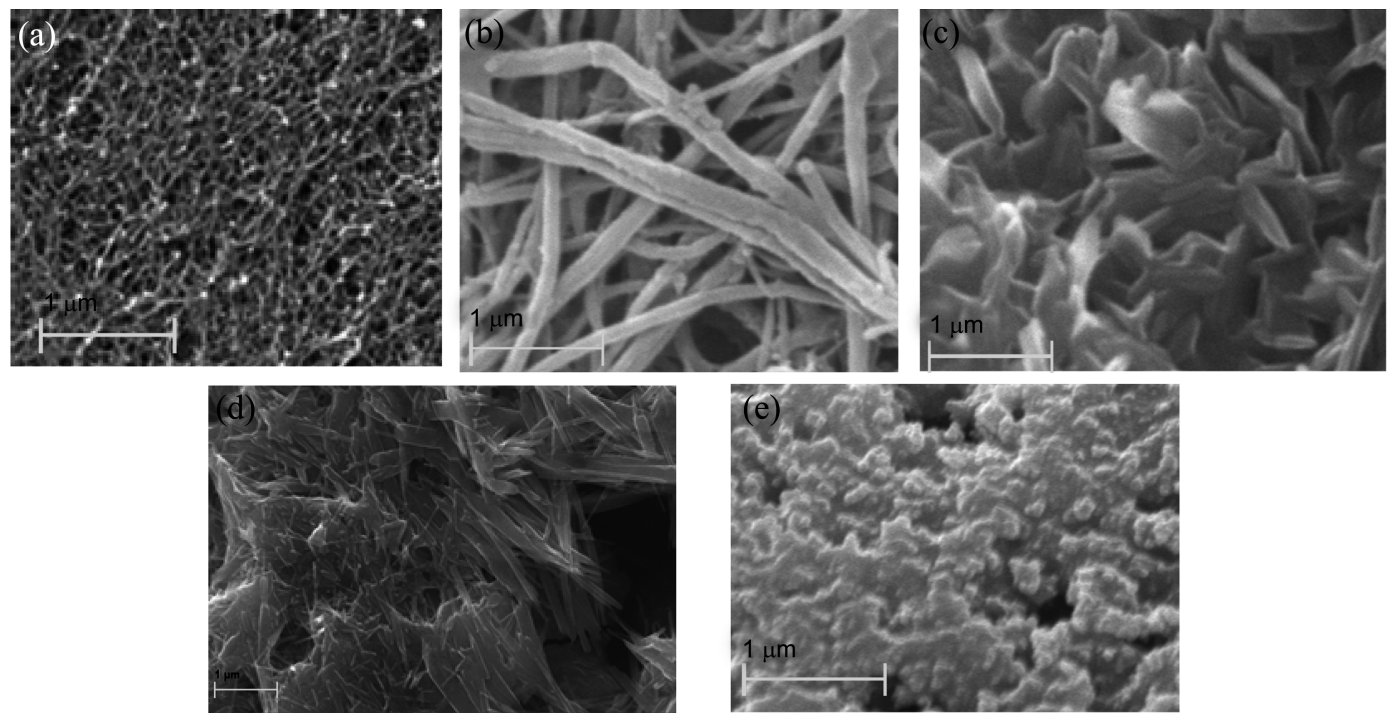

Figure 2. SEM image of (a) pure SWCNT, (b) pure MWCNT, ${ }^{47}$ (c)TEAP IL, (c) SWCNT-TEAP composite and (d) MWCNT-TEAP composite. $^{47}$

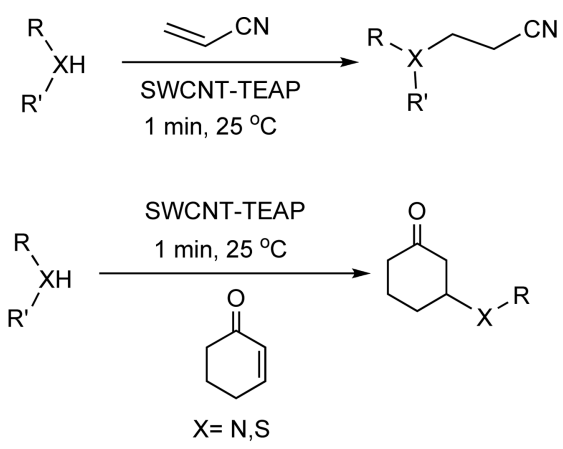

$\mathrm{R}, \mathrm{R}^{\prime}=\mathrm{H}, \mathrm{N}$-alkyl, $\mathrm{N}$-arylpiperazines, aliphatic, aromatic, heterocycles.

Scheme 1. The conjugate addition of amines and thiols to $\alpha, \beta-$ unsaturated nitriles and carbonyl compounds using the bucky gel.

This supports the fact that TEAP uniformly covers the outer surface of the SWCNT in SWCNT-TEAP, and the CNT bundles are weakly interlocked with one another allowing the formation of gels. These results are in good agreement with the reported results. ${ }^{20,24}$ To show the utility of bucky gel in organic reactions, we studied Michael reactions. To study the effectiveness of the environmentally friendly catalyst (bucky gel) for $\mathrm{C}-\mathrm{N}$ and $\mathrm{C}-\mathrm{S}$ bond forming reaction, herein we report the conjugate addition of amines and thiols to $\alpha, \beta$-unsaturated nitriles and carbonyl compounds using the bucky gel catalyst (Scheme 1).

This protocol was successfully applied to catalyze the Michael addition of various substituted piperazines, aliphatic, aromatic amines, imidazoles, and thiols with $\alpha, \beta$-unsaturated nitriles or carbonyl compounds. The standardized results are represented in Table 1, which reveal that the yield of the desired product increases with the addition of SWCNTTEAP catalyst at solvent free condition. Thus, a probable mechanism for the reaction using bucky gel as a catalyst for both the thia-Michael and the aza-Michael reaction is suggested. The enhanced reactivity in the bucky gel is attributed due to the inherent Brønsted and Lewis acidity of the $\left[\mathrm{Et}_{3} \mathrm{NH}\right]^{+}$cation, which is responsible for making the $\mathrm{NH}$ and $\mathrm{SH}$ bond weaker and thus enhances the nucleophilicity of sulfur for addition to electron-deficient alkenes.

In both aza and thia-Michael reactions, product yield increased by SWCNT-TEAP, due to more surface area of SWCNT-TEAP. Hence, we catalysed the rest of the Michael addition of various substituted piperazines, aliphatic, aromatic amines, imidazoles, and thiols with $\alpha, \beta$-unsaturated nitriles or carbonyl compounds in the presence of SWCNT-TEAP; results of the reactions are summarized in Tables 2. As documented in our previous work, ${ }^{47}$ we have developed a catalyst for the synthesis of Michael reactions under solventfree conditions, commonly known as bucky gel by inter-

Table 1. The Michael reaction for entry 1 in Table 2

\begin{tabular}{cccccc}
\hline Entry & Catalyst & Temperature & Time for complete conversion & Yield (\%) & Reference \\
\hline 1 & No catalyst & $25^{\circ} \mathrm{C}$ & $24 \mathrm{~h}$ & 0 & 0 \\
2 & SWCNT & $25^{\circ} \mathrm{C}$ & $24 \mathrm{~h}$ & 0 & 47 \\
3 & MWCNT & $25^{\circ} \mathrm{C}$ & $24 \mathrm{~h}$ & 80 & \\
4 & TEAP & $25^{\circ} \mathrm{C}$ & $1 \mathrm{~min}$ & 97 & 47 \\
5 & SWCNT-TEAP & $25^{\circ} \mathrm{C}$ & $1 \mathrm{~min}$ & 96 & 47 \\
6 & MWCNT-TEAP & $25^{\circ} \mathrm{C}$ & $1 \mathrm{~min}$ & 2 & \\
\hline
\end{tabular}


Table 2. Michael reaction catalysed by bucky gel

Entry

${ }^{a}$ Yields determined by GC analysis and catalysed by the SWCNT-TEAP. ${ }^{b}$ Yields determined by GC analysis and catalysed by the MWCNT-TEAP [ref. 47]

acting MWCNT and TEAP together. Whereas, in this present piece of work we have developed a bucky gel as a result of interaction between SWCNT and TEAP, another catalyst for Michael reactions under solvent free condition. In order to confirm the efficiency between these two bucky gels as a catalyst, we compared the yield of aza and thia-Michael reactions catalyzed by SWCNT-TEAP and MWCNT-TEAP ${ }^{44}$ as shown in Table 1 and Table 2. These tables reflect that the higher yield is obtained in the case of SWCNT-TEAP as compared to MWCNT-TEAP. It is suggested that increased yield in case of SWCNT-TEAP might be due to more surface area of SWCNT as compared to MWCNT. ${ }^{47-49}$ We then propose both the CNTs (SWCNT and MWCNT)-TEAP to be an excellent catalyst for the reaction medium, whereas SWCNT-TEAP serves as a better catalyst for the reactions.

\section{Conclusions}

We here by conclude that SWCNT and TEAP interact with each other to develop a new catalytic system, which is justified to serve as a catalyst for the synthesis of Michael reactions under solvent-free conditions. This catalyst offers many advantages including; (a) cost effectiveness and an environmentally benign reagent, (b) green pathway for organic synthesis by eliminating the use of hazardous and toxic organic solvents, (c) applicable to a wide range of substituted aldehydes, and (d) mild temperature reaction condition. And, SWCNT-TEAP proves to be as an accomplished catalyst for the reaction medium. Hence, SWCNT-TEAP catalyst serves as a convincing green, facile and superior method for the synthesis, providing higher yields, simple reaction conditions, shorter reaction times, easy work up and also offers recyclability. It also proves that SWCNT-TEAP as catalyst synthesized the Michael reaction in more yield as compared with MWCNT-TEAP.

Acknowledgments. We gratefully acknowledge the National Research Foundation of Korea (NRF) grant funded by the Korea government (MSIP) (NRF-2010-0027963) and This work was supported by the New \& Renewable Energy of the Korea Institute of Energy Technology evaluation and Planning (KETEP) grant funded by the Korea government Ministry of knowledge Economy (No. 96002011003) and by Ministry of Knowledge Economy (MKE), Korea as a project, "Full color 360 degree 3D holographic video making technology" and by ministry of Culture, Sports and Tourism (MCST) and Korea Creative Contents Agency (KOCCA) in the Culture Technology Research \& Development Program 2012 in part and by Kwangwoon University 2014.

\section{References}

1. Iijima, S.; Ichihashi, T. Nature 1993, 363, 603.

2. Iijima, S. Nature 1991, 354, 56.

3. Baughman, R. H.; Zakhidov, A. A.; de Heer, W. A. Science 2002, 297, 787.

4. Bethune, D. S.; Kiang, C. H.; de Vries, M. S.; Gorman, G.; Savoy, R.; Vasquez, J.; Bayers, R. Nature 1993, 363, 605.

5. Welton, T. Chem. Rev. 1999, 99, 2071.

6. Wasserscheid, P.; Keim, W. Angew. Chem. Int. Ed. 2000, 39, 3772.

7. Attri, P.; Venkatesu, P.; Hofman, T. J. Phys. Chem. B 2011, 115, 10086.

8. Attri, P.; Pal, M. Green Chem. Lett. Rev. 2010, 3, 249.

9. de Diego, T.; Lozano, P.; Gmouh, S.; Vaultier, M.; Iborra, J. L. Biomacromolecules 2005, 6, 1457.

10. Yau, H. M.; Croft, A. K. Annu. Rep. Prog. Chem. Sect B: Org. Chem. 2012, 108, 272.

11. Chen, X.; Liu, J.; Wang, J. Anal. Methods 2010, 2, 1222.

12. Härdelin, L.; Thunberg, J.; Perzon, E.; Westman, G.; Walkenström, P.; Gatenholm, P. J. App. Polym. Sci. 2012, 125, 1901.

13. Attri, P.; Venkatesu, P. Process Biochemistry 2013, 48, 462.

14. Constantinescu, D.; Weingärtner, H.; Herrmann, C. Angew Chem. In. 2007, 46, 8887.

15. Attri, P.; Venkatesu, P.; Kumar, A. Org. Biomol. Chem. 2012, 10, 7475.

16. Fukushima, T.; Kosaka, A.; Ishimura, Y.; Yamamoto, T.; Takigawa, T.; Ishii, N.; Aida, T. Science 2003, 300, 2072.

17. Fukushima, T.; Aida, T. Chem.-Eur. J. 2007, 13, 5048.

18. Mohammadi, M.; Foroutan, M. Phys. Chem. Chem. Phys. 2013, 15,2482 .

19. Chen, Y.; Bai, L.; Zhou, C.; Lee, J.-M.; Yang, Y. Chem. Commun. 2011, 6452.

20. Hong, S. H.; Tung, T. T.; Trang, L. K. H.; Kim, T. Y.; Suh, K. S. Colloid Polym. Sci. 2010, 288, 1013.

21. Zhou, X.; Wu, T.; Ding, K.; Hu, B.; Hou, M.; Han, B. Chem. Commun. 2009, 1897.

22. Liu, Y.; Yu, L.; Zhang, S.; Yuan, J.; Shi, L.; Zheng, L. Colloids and Surfaces A: Physicochem. Eng. Aspects 2010, 359, 66.

23. Polo-Luque, M. L.; Simonet, B. M.; Valcárcel, M. Trends Anal. Chem. 2013, 47, 99.

24. Tunckol, M.; Durand, J.; Serp, P. Carbon 2012, 50, 4303.

25. Wang, J. Y.; Chu, H. B.; Li, Y. ACS Nano 2008, 2, 2540.

26. Kocharova, N.; Aaritalo, T.; Leiro, J.; Kankare, J.; Lukkari, J. Langmuir 2007, 23, 3363.

27. Lee, J.; Aida, T. Chem. Commun. 2011, 6757. 
28. Zhou, X. S.; Wu, T. B.; Ding, K. L.; Hu, B. J.; Hou, M. Q.; Han, B. X. Chem. Commun. 2009, 1897.

29. Crescenzo, A. D.; Demurtas, D.; Renzetti, A.; Siani, G.; Maria, P. D.; Meneghetti, M.; Prato, M.; Fontana, A. Soft Matter 2009, 5, 62.

30. Fukuda, K.; Sekitani, T.; Zschieschang, U.; Klauk, H.; Kuribara, K.; Yokota, T.; Sugino, T.; Asaka, K.; Ikeda, M.; Kuwabara, H.; Yamamoto, T.; Takimiya, K.; Fukushima, T.; Aida, T.; Takamiya, M.; Sakurai, T.; Someya, T. Adv. Funct. Mater. 2011, 21, 4019.

31. Tang, X.-J.; Yan, Z.-L.; Chen, W.-L.; Gao, Y.-R.; Mao, S.; Zhang, Y.-L.; Wang, Y.-Q. Tetrahedron Lett. 2013, 54, 2669.

32. Han, L. B.; Tanaka, M. Chem. Commun. 1999, 395.

33. Ahmad, Y. E.; Laurent, E.; Maillet, P.; Talab, A.; Teste, J. F.; Dohkan, R.; Tran, G.; Ollivier, V. J. Med. Chem. 1997, 40, 952.

34. Hashemi, M. M.; Eftekhari-Sis, B.; Abdollahifar, A.; Khalili, B. Tetrahedron 2006, 62, 672.

35. Azizi, N.; Saidi, M. R. Tetrahedron 2004, 60, 383.

36. Surendra, K.; Krishnaveni, N. S.; Sridhar, R.; Rao, K. R. Tetrahedron Lett. 2006, 47, 2125.

37. Yang, L.; Xu, L.-W.; Zhou, W.; Li, L.; Xia, C.-G. Tetrahedron Lett. 2006, 47, 7723.

38. Verma, A. K.; Attri, P.; Chopra, V.; Tiwari, R. K.; Chandra, R. Monatsh Chem. 2008, 139, 1041.
39. Leighton, C. M.; Delp, S. A.; Blue, E. D.; Gunnoe, T. B. Organometallics 2007, 26, 1483.

40. Roy, A.; Kundu, D.; Kundu, S. K.; Majee, A.; Hajra, A. The Open Catalysis Journal 2010, 3, 34.

41. Saidi, M. R.; Pourshojaei, Y.; Aryanasab, F. Synth. Comm. 2009, 39, 1109 .

42. Choudhary, V. R.; Dumbre, D. K.; Patil, S. K. RSC Adv. 2012, 2 , 7061.

43. Liu, X.-B.; Lu, M.; Lu, T.-T.; Gu, G.-L. J. Chin. Chem. Soc. 2010, $57,1221$.

44. Attri, P.; Bhatia, R.; Arora, B.; Kumar, N.; Park, J. H.; Baik, K. Y.; Lee, G. J.; Kim, I. T.; Koo, J. H.; Choi, E. H. Mater. Res. Bull. 2014, DOI.org/10.1016/j.materresbull.2014.03.025.

45. Pawley, J. B. Handbook of Biological Confocal Microscopy; Kluwer Academic Publishers: Dordrecht, 1995.

46. Du, P.; Liu, S.; Wu, P.; Cai, C. Electrochim. Acta 2007, 52, 6534.

47. Madani, S. Y.; Mandel, A.; Seifalian, A. M. Nano Rev. 2013, 4, 21521.

48. Wanga, G.; Linga, Y.; Qiana, F.; Yanga, X.; Liu, X.-X.; Li, Y. J. Pow. Sour. 2011, 196, 5209.

49. Mercer, R. R.; Hubbs, A. F.; Scabilloni, J. F.; Wang, L.; Battelli, L. A.; Friend, S.; Castranova, V.; Porter, D. W. Particle and Fibre Toxicology 2011, 8, 21. 